\title{
Pilot study of decision support tools on breast cancer chemoprevention for high- risk women and healthcare providers in the primary care setting
}

Rita Kukafka ${ }^{1,2,3^{*}}$ D, Jiaqi Fang ${ }^{1}$, Alejandro Vanegas ${ }^{2}$, Thomas Silverman ${ }^{2}$ and Katherine D. Crew ${ }^{1,2,3}$

\begin{abstract}
Background: Breast cancer chemoprevention can reduce breast cancer incidence in high-risk women; however, chemoprevention is underutilized in the primary care setting. We conducted a pilot study of decision support tools among high-risk women and their primary care providers (PCPs).

Methods: The intervention included a decision aid (DA) for high-risk women, RealRisks, and a provider-centered tool, Breast Cancer Risk Navigation (BNAV). Patients completed validated surveys at baseline, after RealRisks and after their PCP clinical encounter or at 6-months. Referral for high-risk consultation and chemoprevention uptake were assessed via the electronic health record. The primary endpoint was accuracy of breast cancer risk perception at 6-months.

Results: Among 40 evaluable high-risk women, median age was 64.5 years and median 5-year breast cancer risk was 2.19\%. After exposure to RealRisks, patients demonstrated an improvement in accurate breast cancer risk perceptions $(p=0.02)$, an increase in chemoprevention knowledge $(p<0.01)$, and $24 \%$ expressed interest in taking chemoprevention. Three women had a high-risk referral, and no one initiated chemoprevention. Decisional conflict significantly increased from after exposure to RealRisks to after their clinical encounter or at 6 -months $(p<0.01)$. Accurate breast cancer risk perceptions improved and was sustained at 6-months or after clinical encounters. We discuss the side effect profile of chemoprevention and the care pathway when RealRisks was introduced to understand why patients experienced increased decision conflict.

Conclusion: Future interventions should carefully link the use of a DA more proximally to the clinical encounter, investigate timed measurements of decision conflict and improve risk communication, shared decision making, and chemoprevention education for PCPs. Additional work remains to better understand the impact of decision aids targeting both patients and providers.
\end{abstract}

Trial registration: ClinicalTrials.gov Identifier: NCT02954900 November 4, 2016 Retrospectively registered.

Keywords: Chemoprevention, Breast cancer, Decision support, Decision conflict, Risk communication, Decision aids

\footnotetext{
* Correspondence: rk326@cumc.columbia.edu

${ }^{1}$ Columbia University, Mailman School of Public Health, 622 West 168th

Street, PH-20, New York, NY 10032, USA

${ }^{2}$ Columbia University, College of Physicians and Surgeons, New York, NY,

USA

Full list of author information is available at the end of the article
}

(c) The Author(s). 2018 Open Access This article is distributed under the terms of the Creative Commons Attribution 4.0 International License (http://creativecommons.org/licenses/by/4.0/) which permits unrestricted use, distribution, and reproduction in any medium, provided you give appropriate credit to the original author(s) and the source, provide a link to the Creative Commons license, and indicate if changes were made. The Creative Commons Public Domain Dedication waiver (http://creativecommons.org/publicdomain/zero/1.0/) applies to the data made available in this article, unless otherwise stated. 


\section{Background}

Breast cancer is the most common cancer among women in the United States, with an estimated 1 in 8 women developing invasive breast cancer during her lifetime [1]. More than 252,700 new cases and 40,610 deaths due to breast cancer are expected to occur among U.S. women in 2017 [2]. Women with a 5-year invasive breast cancer risk greater than $1.67 \%$ or a lifetime risk greater than $20 \%$ based upon the Gail model [3] have the option of taking a chemopreventive medication. Chemoprevention with selective estrogen receptor modulators (SERMs) and aromatase inhibitors (AIs) has been shown to reduce invasive breast cancer risk by up to $50-65 \%$ among high-risk women in randomized controlled trials [4-7]. Grounded in strong evidence, the U.S. Preventive Services Task Force (USPSTF), National Comprehensive Cancer Network $(\mathrm{NCCN})$, American Society for Clinical Oncology (ASCO), and the National Institute for Health and Care Excellence (NICE) recommend that clinicians discuss preventive therapy with high-risk women [8-11]. However, uptake of SERMs or AIs for the prevention of breast cancer is extremely low [12]. In a meta-analysis of therapeutic agent uptake to prevent breast cancer among women at increased risk, Smith et al. found that uptake was $25.2 \%$ among women screened for clinical trials, but only $8.7 \%$ (95\% CI, 6.8-10.9) in non-trial settings [13].

Decision aids can help to improve communication between providers and patients, and can assist patients clarify how important the potential benefits and harms are to them. However, studies that examined the effect of decision aids on SERM use found that while knowledge about risks and benefits increased, decisions were rarely influenced. Guide to Decide, a decision aid that informed high-risk postmenopausal women about potential chemoprevention benefits and side effects resulted in no tamoxifen uptake and only $0.5 \%$ uptake of raloxifene [14]. The Ready, Set, GO GAIL! study involved PCPs using the Gail model to screen more than 5700 women [15]. Although 868 (15.2\%) women were classified as high-risk for breast cancer, only $14.7 \%$ were referred for risk counseling, $6.4 \%$ attended the consultation, and $2 \%$ started chemoprevention. The BreastCARE randomized controlled trial revealed that more women were referred for high-risk consultation in the intervention group compared to controls, however there was limited communication about chemoprevention documented in the medical record [16].

The literature is surprisingly scant on decision aids targeting both patients and providers [17], and most studies on chemoprevention decision-making have been based on hypothetical scenarios to evaluate levels of interest, which may ineffectively predict actual uptake [12]. Studies confirm the importance of the primary care provider recommendation for the decision to take a SERM for breast cancer risk reduction [18-20]. However, this recommendation was more likely to be followed when SERM use discussions assess patient attitudes toward medication and relate to those when discussing chemoprevention options to make the information relevant to the patients [18]. Since breast cancer chemoprevention is not generally diffused in the primary care setting, more effective tools are needed to inform both providers and patients about the risks and benefits of SERMs and AIs, help them to identify available options and deliberate those options in light of patients values and preferences.

In this paper, we report results of a pilot study conducted to examine the efficacy of two decision support tools, the RealRisks decision aid (DA) for patients and the Breast cancer risk NAVigation (BNAV) decision support tool for primary care providers (PCPs) [21]. Providers received $B N A V$ decision support at the time their patient completed RealRisks, thus the tools when integrated into clinical workflow were intended to complement one another. We sought to determine whether our decision support tools increase patient's accuracy of breast cancer risk perceptions, and breast cancer and chemoprevention knowledge. We also sought to identify referrals for consultation at a high-risk breast clinic, and chemoprevention uptake among women at high risk for breast cancer post intervention.

\section{Methods}

\section{Study population and eligibility criteria}

Women $(N=19,026)$ presented for screening mammography at Columbia University Medical Center (CUMC) in New York, NY between 2014 and 2016 (Fig. 1) [22]. Among them, 3743 (19.7\%) were approached for enrollment into the Know Your Risk: Assessment at Screening (KYRAS) for breast cancer study, and 3077 (82.2\%) consented and completed a baseline survey on demographics and breast cancer risk factors. Of the 3077, 511 (16.6\%) women were identified as high-risk for breast cancer according to the Gail model. These high-risk women were informed of their breast cancer risk status and given a brochure to the CUMC breast clinic for a high-risk consultation. A subset of participants $(N=50)$ from this larger study was recruited into a single-arm pilot intervention study of the chemoprevention decision support tools. Eligibility criteria for the pilot included the following: 1) women, age 35-75 years; 2) 5-year invasive breast cancer risk $\geq 1.67 \%$ based upon the Gail model [3]; 3) having a primary care provider (PCP) at CUMC; 4) English or Spanish-speaking. Those with any history of breast cancer or with current or prior use of a selective estrogen receptor modulator (SERM) or aromatase inhibitor (AI) for breast cancer risk reduction were excluded. Having a PCP at CUMC was an inclusion criteria to ensure that both patient and provider would have access to the decision support tools and we could 


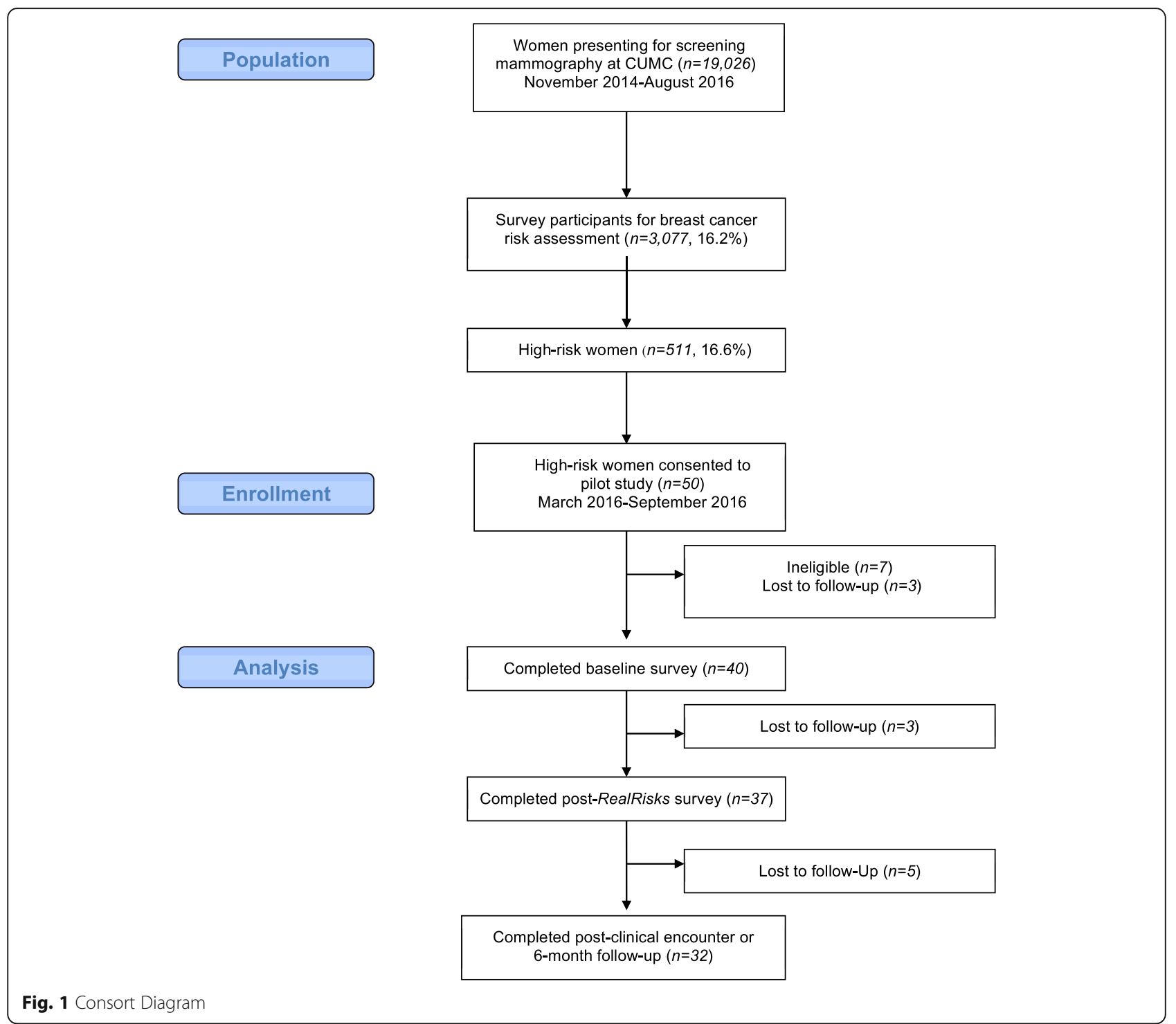

access the electronic health record at CUMC. Providers from primary care clinics at CUMC were invited to participate if they had an identified patient eligible for breast cancer chemoprevention. This study was approved by the institutional review board at CUMC and registered at clinicaltrials.gov (NCT02954900).

\section{Study interventions}

RealRisks is a web-based patient-centered decision aid (DA) designed to increase the following: 1) accurate breast cancer risk perceptions; 2) breast cancer and chemoprevention knowledge; and 3) self-efficacy to engage in a collaborative dialogue about breast cancer risk and chemoprevention decisions (Fig. 2). We designed RealRisks by involving both patients and providers in multiple design sessions and usability studies to arrive at guiding principles that focused on the following: 1) options for providing information of breast cancer risk and chemoprevention, 2) "interactive games" to communicate breast cancer risk, and 3) patient preference elicitation to weigh the risks and benefits of SERMs and AIs (Fig. 2). An early prototype was evaluated in focus groups among women of various ethnicities from New York City. In this evaluation, accuracy of breast cancer risk perception (perceived minus actual breast cancer risk according to the Gail model [3]) significantly improved after interacting with RealRisks, even in the subgroup of women with low numeracy [23]. After the initial prototype was developed, we conducted usability studies with English- and Spanishspeaking women to determine how they navigated, engaged with and understood the information in RealRisks [21]. Using surveys, think-aloud protocols, and subject recordings, we identified several themes relating to the usability of RealRisks, specifically in the content, ease of use, 
A
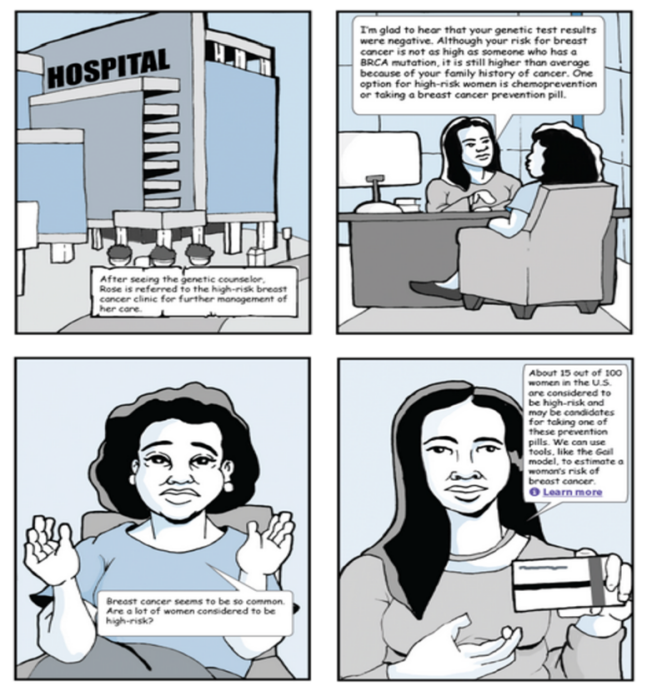

B

\section{Risk Game: Lifetime Risk of Breast Cancer}

Of the 100 women below, some will have breast cancer but you

won't know which ones. Click on the women until you find one

with breast cancer. Women with breast cancer will turn red when

you click on them.

Click the people until you find out!

Lifetime Risk

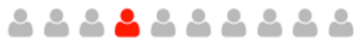

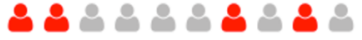

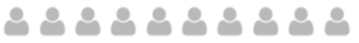

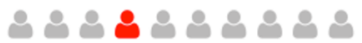

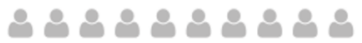

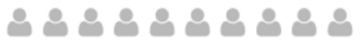

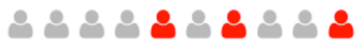

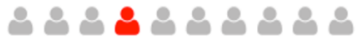

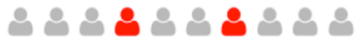

के

\section{C}

Pros and Cons of Chemoprevention Pills

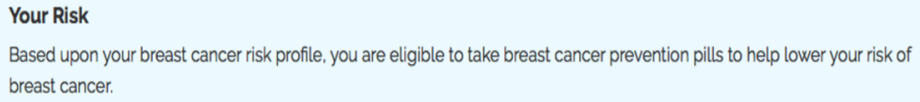

Based upon your breast cancer risk profile, you are eligible to take breast cancer prevention pills to help lower your risk of breast cancer.

\section{Drag the slider to reflect how you feel about each item.}

- If you are considering whether to take a breast cancer prevention pill, how important are the following items to you when making that health decision?

- Use your responses to decide if taking breast cancer prevention pills is right for you

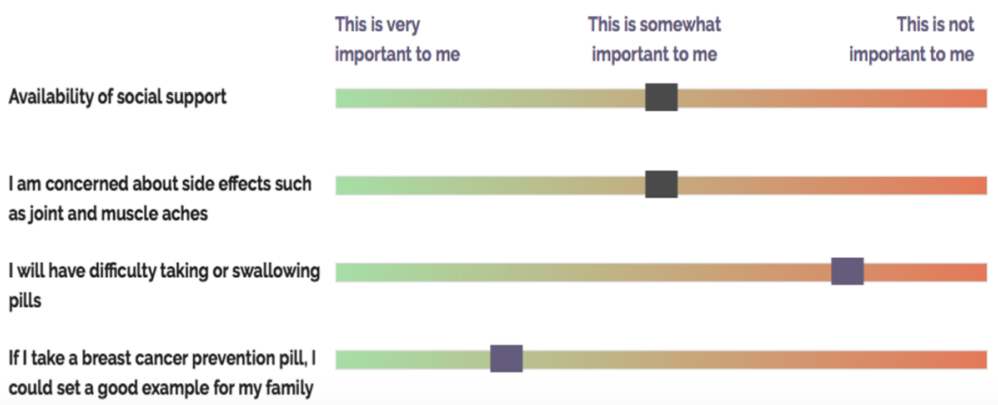

Fig. 2 Screenshots of RealRisks, patient-centered decision aid: (a) Graphic novel-style narrative; (b) Interactive game to communicate breast cancer risk; (c) Preference elicitation about the risks and benefits of chemoprevention

and navigability of the application. By conducting studies in two languages with a diverse multi-ethnic population, we were able to implement interface changes to make RealRisks accessible to users with varying levels of health literacy and acculturation.

RealRisks includes the option to view the material in a text-heavy, or "information dense," format or in an "information light" format that primarily uses pictures. The
DA also has an audio option and Spanish translations. The educational modules include: 1) Breast cancer risk (breast cancer risk factors, calculation of personal breast cancer risk according to the Gail model, interactive games on risk communication); and 2) Chemoprevention (what is chemoprevention, risks and benefits of SERMs and AIs for chemoprevention, preference elicitation of chemoprevention). Through the RealRisks DA, 
we collect information on breast cancer risk factors to calculate a patient's Gail risk score. We also collect factors that influence the decision making about chemoprevention through the preference elicitation game. RealRisks generates an action plan for patients summarizing their personalized breast cancer risk profile and preferences for chemoprevention. A provider view of the action plan, which is much shorter in length and designed to be actionable, is also made available to the provider through $B N A V$.

The provider-facing $B N A V$ tool (Fig. 3) uses a twopronged strategy to improve knowledge among healthcare providers about breast cancer risk assessment and chemoprevention. After patients complete RealRisks, their providers receive the tailored action plan via secure health messaging and are offered access the web-based $B N A V$ toolbox. Based on the Theory of Planned Behavior [24], the toolbox contains a collection of information and resources that includes: 1) up-to-date guidelines and interactive educational presentations (attitudes); 2) video testimonials from experts in the field and a social component that enables a provider to compare his or her performance against aggregate, anonymous data of his or her peers (subjective norm); and 3) a repository of their patients' breast cancer risk, together with the action plans generated by the patients' interactions with RealRisks (perceived behavioral control). The BNAV chemoprevention module includes resources on breast cancer risk assessment, benefits and risks of chemoprevention, and how to manage the side effects of SERMs and AIs. Over time, other modules have been integrated into RealRisks (genetic testing for hereditary breast and ovarian cancer syndrome (HBOC), screening recommendations and guidelines, and risky health behaviors and lifestyle modification) and $B N A V$ (genetic testing for HBOC, screening recommendations and guidelines, and patient-centered care), which allow providers to self-direct viewing resources outside of the clinical encounter. Each module takes about 10-20 min to view and can be completed during multiple sittings. To evaluate BNAV, individual interviews were conducted with 10 PCPs [25]. We found that few providers routinely used breast cancer risk calculators in their practice and they expressed concerns about the added burden of incorporating these tools into the clinic visit and being unfamiliar with chemoprevention.

\section{Outcome measures and data collection}

High-risk women completed self-administered questionnaires at baseline, immediately after completing RealRisks, and 6 months after baseline or after the clinical encounter with their PCP. Health literacy, subjective and objective numeracy, and acculturation were assessed at baseline using brief validated measures of each construct
$[26,27]$. Breast cancer and chemoprevention knowledge was assessed using a 13-item scale, with adequate knowledge defined as at least 50\% correct responses [28]. A participant's confidence in communicating with her PCP was measured as an average of three items (range: 0-100\%) [29]. Breast cancer risk perception was assessed by four items of absolute estimate, comparative risk assessed on a 3-point Likert scale, and numeric 5-year and lifetime risk on a scale of 0 to $100 \%$ [30]. Breast cancer worry was assessed using responses to two questions on a 7-point Likert scale [31, 32]. Self-efficacy was measured as an average of 5 items to assess perceived confidence in making a choice (range: $0-100 \%$ ) [33]. Decision conflict was measured using the low literacy version of the Decision Conflict Scale (DCS) after exposure to RealRisks and at 6 months or after the PCP clinical encounter. The total score was calculated by averaging the 10 individual item scores so that higher scores indicated higher decisional conflict (range: 0-100) [33]. Scores lower than 25 on the scale are associated with implementing decisions whereas scores greater than 37.5 indicate high decision conflict, which is characterized by decision delay and/or uncertainty. Subscores of the scale that focus on factors contributing to uncertainty (e.g., feeling uncertain, uninformed, unclear about values, and unsupported in decision-making) were also reported on a range from 0 to 100 [33]. Behavioral intent for chemoprevention was assessed as previously described [14]. Referral to the high-risk breast clinic and chemoprevention uptake were assessed at 6 months via the electronic health record (EHR).

\section{Statistical analysis}

Our primary endpoint was accuracy of perceived breast cancer risk, defined as perceived lifetime risk within $\pm 10 \%$ of actual lifetime risk according to the Gail model, at 6 months compared to baseline. The 10\% range on either side of the Gail model risk estimate has been commonly used to provide a reasonable margin within which responses are labeled as accurate [34-37].McNemar's test was used to compare accurate breast cancer risk perception and adequate breast cancer and chemoprevention knowledge at baseline and follow-up. Paired t-tests were utilized to assess changes in continuous measures of differences in perceived and actual lifetime breast cancer risk, breast cancer and chemoprevention knowledge, breast cancer worry, self-efficacy, and decision conflict from baseline to post-RealRisks, from baseline to post-clinical encounter or 6 months, and from post-RealRisks to post-clinical encounter or 6 months. All analyses were conducted using SAS version 9.4 (Cary, NC) and a $p$-value $<0.05$ was considered to be statistically significant. 
A

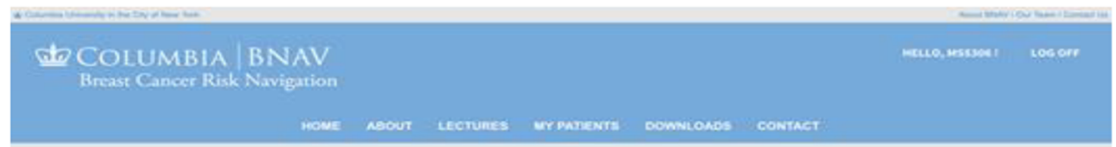
CHEMOPREVENTION TOPIC 1:
BREAST CANCER ASSESSMENT

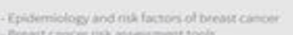

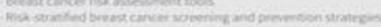

chemes

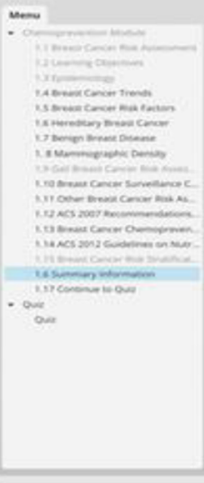

Summary Information

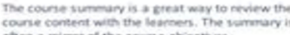

Breast cancer is common and there are relatively few

modifable risk factors for this disease.

Several breast cancer risk assessment tools are available

for use in the clinical setting.

10I Breast cancer risk assessment can inform a risk-stratified approach to breast cancer screening and prevention.

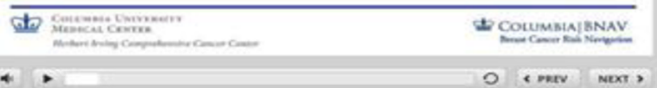

B

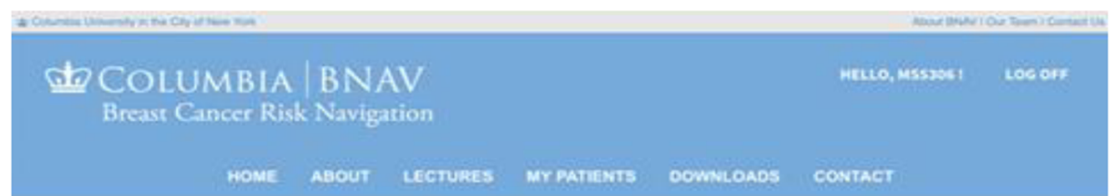

DOWNLOADS / REFERENCES

Chemperenvertion

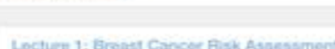

1) Endemiology

2. Brenst caver nat bacion

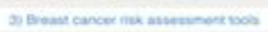

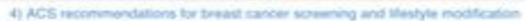

Locture 2: Broast Cancet Chemoprevontion with Antiestrogbing

Lecture 3: Manaperment of NH-LCIS-DCis

Gonetic Testing

Patient Ceeteres Cary

Screening

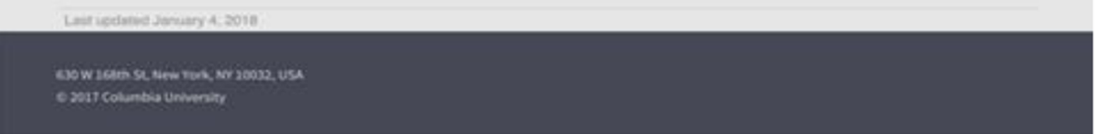

Fig. 3 Screenshots of BNAV (Breast cancer risk NAVigation) provider-centered tool: (a) Slide presentations; (b) Link to download references 


\section{Results}

\section{Participants}

Table 1 summarizes the baseline characteristics of the forty women who met all eligibility criteria and completed the baseline survey. The majority (95\%) were postmenopausal women with a median age of 64.5 years (range, 4972 years). Our sample was racially and ethnically diverse with $42.5 \%$ Hispanics, $40.0 \%$ non-Hispanic white, $12.5 \%$ non-Hispanic black and 5.0\% Asian or other. The mean 5 -year invasive breast cancer risk, based on the Gail model, was $2.38 \pm 0.81 \%$. Thirty-five percent reported having benign breast disease and half of them had a first-degree family history of breast cancer. Compared to non-Hispanic women, Hispanics were less educated and had lower acculturation, health literacy, and numeracy.

\section{Patient reported outcomes at baseline, post-intervention and 6 months.}

Table 2 summarizes the patient-reported outcomes at baseline, post-intervention (RealRisks) and at 6 months or after the clinical encounter with their primary care provider (PCP). At baseline, the majority of patients (75\%) overestimated their perceived risk of breast cancer. Accurate breast cancer risk perceptions increased from $38 \%$ at baseline to $63 \%$ at 6 months $(p=0.03)$. The mean difference between perceived and actual lifetime breast cancer risk according to the Gail model decreased from $23.7 \%$ (SD 24.7) at baseline to $12.1 \%$ (SD 18.1) post-RealRisks $(p=0.01)$. After exposure to RealRisks, there was no significant change in breast cancer knowledge; however, mean chemoprevention knowledge scores significantly improved from baseline to follow-up, but this difference diminished over time ( 0.71 at baseline, 3.69 post-RealRisks, and 1.94 at 6 months, $p<0.01$ for both comparisons). Breast cancer worry and self-efficacy in chemoprevention decision making did not change significantly. However, decision conflict increased from post-intervention to 6 months $(17.92$ vs. $43.44, p<.01)$. After exposure to RealRisks, 23 women (64\%) experienced some or no decisional conflict with scores below 25 compared with 9 women (28\%) at 6 months. Sub-scores for every decisional conflict domain were in the same direction, with significantly higher scores at 6 months compared to post-intervention. In terms of chemoprevention intention, $24 \%$ of participants expressed interest in taking chemoprevention, $47 \%$ were unsure, and 29\% were not interested. Three (7.5\%) women were referred for high-risk consultation and none had initiated chemoprevention at 6 months. There were no significant differences in patient-reported outcomes between Hispanic and non-Hispanic women, except that Hispanic women tended to have higher mean breast cancer worry scores (4.72 vs. 2.09 at baseline, 5.02 vs. 2.50 post-RealRisks, and 4.82 vs. 2.11 at 6 months, respectively).

\section{Discussion}

Our intervention demonstrated a significant improvement in accuracy of breast cancer risk perception and an increase in chemoprevention knowledge. It was notable that accuracy of breast cancer risk perceptions significantly improved post RealRisks, and was sustained at 6 months. The finding that decision conflict significantly increased from post-intervention to 6 months or after clinical encounters with PCPs was unexpected. The literature is not clear on why the decision to accept or reject chemoprevention would become more difficult with the passage of time. Possible explanations may reside with the decision itself, the care pathway when the DA was introduced, or a combination of both.

Decision conflict is not simply recognition that advantages and disadvantages exist for any given option. It is also an undesirable state of discomfort and internal conflict experienced when facing a difficult decision [38]. The decision to take chemoprevention can raise an undesirable state of discomfort given the perception that SERMs or AIs are "cancer drugs" and tradeoffs between the risks and benefits of these medications. It has been proposed that the side effect profile of chemoprevention medications, coupled with wide-ranging concerns about the emotional impact of taking a medication, leads to medication avoidance. Specifically, women might decide to avoid chemoprevention because of the affect-laden responses associated with the term "side effect" and their belief that these medications will increase, rather than decrease, their level of health-related stress [39]. [40-42] Concerns about possible side effects, such as uterine cancer, thromboembolism, and menopausal symptoms, are the primary reasons why women are reluctant to start breast cancer chemoprevention [43-49]. This may also explain results found in previous studies that improved knowledge may result in women becoming more reluctant to take medications that are associated with potentially harmful health risks $[14,50]$.

It is recognized that negative emotions experienced while making a choice involving difficult tradeoffs can potentially impact decision conflict over time. The judgment and decision-making literature suggests that people can react to emotionally laden decisions by altering the amount or content of thought about the decision (emotion-focused coping). This can result in avoidant behaviors, for example declining to make a decision [51], allowing another make the decision for you, or exhibiting an increased tolerance for the status quo option [52]. Studies suggest that decision makers are likely to face between attribute tradeoffs required by decision conflict when the attributes are relatively low in emotional tradeoff difficulty. Conversely, they tend to elude these tradeoffs when attributes are higher in emotional tradeoff difficulty. Thus, it is plausible that increased 
Table 1 Baseline characteristics of high-risk women identified during screening mammography, Columbia University Medical Center (CUMC), New York, NY (Mar 2016-Sept 2016) stratified by Hispanic and non-Hispanic ethnicity

\begin{tabular}{|c|c|c|c|c|}
\hline Patient Characteristics & Hispanics $(N=17)$ & Non-Hispanics ( $N=23)$ & Total $(N=40)$ & $p$-value \\
\hline Age, years, N (\%) & & & & 0.57 \\
\hline$<50$ & $2(11.8)$ & 0 & $2(5.0)$ & \\
\hline $50-59$ & $1(5.9)$ & $4(17.4)$ & $5(12.5)$ & \\
\hline $60-69$ & $10(58.8)$ & $14(60.9)$ & $24(60.0)$ & \\
\hline$>70$ & $4(23.5)$ & $5(21.7)$ & $9(22.5)$ & \\
\hline Median (range) & $64(49-72)$ & $66(50-72)$ & $64.5(49-72)$ & \\
\hline Mean (SD) & $63.1(7.2)$ & $64.3(6.5)$ & $63.8(6.7)$ & \\
\hline Menopausal status, N (\%) & & & & 0.17 \\
\hline Premenopausal/Perimenopausal & $2(11.8)$ & 0 & $2(5.0)$ & \\
\hline Postmenopausal & $15(88.2)$ & $23(100.0)$ & $38(95.0)$ & \\
\hline Race/ethnicity, N (\%) & & & & N/A \\
\hline Hispanic & $17(100.0)$ & 0 & $17(42.5)$ & \\
\hline Non-Hispanic white & 0 & $16(69.6)$ & $16(40.0)$ & \\
\hline Non-Hispanic black & 0 & $5(21.7)$ & $5(12.5)$ & \\
\hline Other & 0 & $2(8.7)$ & $2(5.0)$ & \\
\hline Education level, N (\%) & & & & $<0.01$ \\
\hline High school or less & $11(64.7)$ & $1(4.3)$ & $12(30.0)$ & \\
\hline Some college or bachelors & $4(23.5)$ & $11(47.8)$ & $15(37.5)$ & \\
\hline Graduate or professional degree & $2(11.8)$ & $11(47.8)$ & $13(32.5)$ & \\
\hline Benign breast disease, $N(\%)$ & $7(41.2)$ & $7(30.4)$ & $14(35.0)$ & 0.75 \\
\hline First-degree family history of breast cancer, N (\%) & $12(70.6)$ & $8(34.8)$ & $20(50.0)$ & 0.05 \\
\hline 5-year invasive breast cancer risk, \% & & & & 0.45 \\
\hline Median (range) & $2.01(1.68-5.64)$ & $2.23(1.70-4.55)$ & $2.19(1.68-5.64)$ & \\
\hline Mean (SD) & $2.26(0.92)$ & $2.46(0.72)$ & $2.38(0.81)$ & \\
\hline Lifetime invasive breast cancer risk, \% & & & & 0.57 \\
\hline Median (range) & $7.87(5.25-23.85)$ & $8.85(4.42-14.14)$ & $8.71(4.42-23.85)$ & \\
\hline Mean (SD) & $9.88(4.99)$ & $9.10(2.97)$ & $9.43(3.92)$ & \\
\hline Age of menarche, N (\%) & & & & 0.02 \\
\hline $7-11$ years & $1(5.9)$ & $8(34.8)$ & $9(22.5)$ & \\
\hline $12-13$ years & $11(64.7)$ & $14(60.9)$ & $25(62.5)$ & \\
\hline $14+$ years & $5(29.4)$ & $1(4.3)$ & $6(15.0)$ & \\
\hline Age of first birth, $N(\%)$ & & & & 0.17 \\
\hline No births & $1(5.9)$ & $2(8.7)$ & $3(7.5)$ & \\
\hline$<20$ years & $4(23.5)$ & $4(17.4)$ & $8(20.0)$ & \\
\hline 20-24 years & $4(23.5)$ & $3(13.0)$ & $7(17.5)$ & \\
\hline $25-29$ years & $4(23.5)$ & $1(4.3)$ & $5(12.5)$ & \\
\hline $30+$ years & $4(23.5)$ & $13(56.5)$ & $17(42.5)$ & \\
\hline Hormone replacement therapy use & $2(11.8)$ & $4(17.4)$ & $6(15.0)$ & 0.93 \\
\hline Mean acculturation (SD) [range, 1-5] & $1.36(0.56)$ & $4.89(0.26)$ & $3.40(1.81)$ & $<.01$ \\
\hline Adequate health literacy, N (\%) & $11(64.7)$ & $22(95.7)$ & $33(82.5)$ & 0.03 \\
\hline Mean subjective numeracy (SD) [range, 1-6] & $3.22(0.19)$ & $4.54(0.67)$ & $4.05(0.95)$ & $<.01$ \\
\hline Adequate numeracy, N (\%) & $6(35.3)$ & 19 (82.6) & $25(62.5)$ & $<.01$ \\
\hline Mean Confidence (SD) [range, 1-10] & $9.48(0.87)$ & $8.95(1.61)$ & $9.18(1.36)$ & 0.20 \\
\hline
\end{tabular}


Table 2 Patient-reported outcomes at baseline, post-intervention (RealRisks) and at 6 months or after the clinical encounter with their primary care providers

\begin{tabular}{|c|c|c|c|c|c|c|}
\hline \multirow[t]{2}{*}{ Patient Outcome Measures } & \multirow{2}{*}{$\begin{array}{l}\text { Baseline (T0) } \\
(N=40)\end{array}$} & \multirow{2}{*}{$\begin{array}{l}\text { Post-RealRisks (T1) } \\
(N=37)\end{array}$} & \multirow{2}{*}{$\begin{array}{l}\text { Post-Clinical Encounter } \\
\text { or } 6 \text { months (T2) } \\
(N=32)\end{array}$} & \multicolumn{3}{|c|}{$p$-value } \\
\hline & & & & T0-T1 & T0-T2 & $\mathrm{T} 1-\mathrm{T} 2$ \\
\hline \multicolumn{7}{|l|}{ Breast Cancer Risk Perception } \\
\hline $\begin{array}{l}\text { Mean difference between perceived and actual } \\
\text { lifetime breast cancer risk (SD) }\end{array}$ & $23.67(24.68)$ & $12.09(18.13)$ & $20.35(27.65)$ & 0.01 & 0.36 & \\
\hline Accurate breast cancer risk perception, N(\%) & $15(39.47)$ & $23(63.89)$ & $20(62.50)$ & 0.02 & 0.02 & \\
\hline \multicolumn{7}{|l|}{ Breast cancer knowledge } \\
\hline Mean number correct (SD) [range, 0-15] & $8.00(1.69)$ & $8.59(1.38)$ & $7.94(1.90)$ & 0.10 & 0.14 & \\
\hline Adequate knowledge, N (\%) & $25(64.10)$ & $30(81.08)$ & $17(53.13)$ & 0.13 & .32 & \\
\hline \multicolumn{7}{|l|}{ Chemoprevention knowledge } \\
\hline Mean number correct (SD) [range, 0-8] & $0.71(1.46)$ & $3.69(2.39)$ & $1.94(1.92)$ & $<.01$ & $<.01$ & \\
\hline Adequate knowledge, N (\%) & $4(10.53)$ & $18(50.00)$ & $9(28.13)$ & $<0.01$ & 0.10 & \\
\hline Mean breast cancer worry (SD) [range, 1-7] & $3.17(1.80)$ & $3.66(2.17)$ & $3.30(2.06)$ & 0.17 & 0.75 & \\
\hline $\begin{array}{l}\text { Mean self-efficacy in chemoprevention (SD) } \\
\text { [range, 0-100] }\end{array}$ & $56(15.81)$ & $60.22(15.45)$ & & 0.24 & & \\
\hline Mean decision conflict (SD) [range, 0-100] & & $17.92(19.51)$ & $43.44(31.30)$ & & & $<.01$ \\
\hline Decision conflict, N (\%) & & & & & & $<.01$ \\
\hline Decision implementation $(<25)$ & & $23(63.9)$ & $9(28.1)$ & & & \\
\hline Unsure about implementation (25-37.5) & & $5(13.9)$ & $5(15.6)$ & & & \\
\hline Decision delay (> 37.5) & & $8(22.2)$ & $18(56.3)$ & & & \\
\hline \multicolumn{7}{|l|}{ Decision conflict sub-scores (SD) (range, 0-100) } \\
\hline Informed subscore & & $9.03(12.66)$ & $24.48(19.74)$ & & & $<.01$ \\
\hline Values clarity subscore & & $8.33(15.24)$ & $23.44(20.02)$ & & & $<.01$ \\
\hline Support subscore & & $7.87(9.33)$ & $17.71(18.66)$ & & & 0.01 \\
\hline \multicolumn{7}{|l|}{ Chemoprevention intention, $N(\%)$} \\
\hline Yes & & $9(24.3)$ & & & & \\
\hline No & & $12(32.4)$ & & & & \\
\hline Unsure & & $17(45.9)$ & & & & \\
\hline High-risk referrals, $N(\%)$ & & & $3(7.5)$ & & & \\
\hline Chemoprevention uptake, $N(\%) 0$ & & & & & & \\
\hline
\end{tabular}

decision conflict from post intervention to 6 months was due to decision avoidance, given that the decision to take chemoprevention requires women to evaluate a number of emotionally laden tradeoffs, mainly between the potential benefits and perceived barriers to chemoprevention medication uptake [53].

As previously asserted in the literature, it is mostly acceptable for decisional conflict to be high if measured shortly after options have been presented, however after the patient has been given the opportunity to incorporate their preferences into the presented options and make a decision, decisional conflict should be low [54]. An equally plausible assertion is that for a patient who prudently weighs competing options decision conflict will be high and even with the passage of time, a rational patient would state that the decision was difficult [55,
56]. Few randomized controlled trials have investigated timed measurements of decision conflict, particularly in underserved populations. Our conclusions are limited due to study design and the lack of a control group in our pilot study, however this area warrants further investigation.

With respect to care pathway, although we tried to integrate the web-based patient and provider decision support tools into clinic workflow, use of the RealRisks DA was not closely linked with the PCP clinical encounter. Many of the patient-reported outcomes, such as accurate breast cancer risk perceptions and chemoprevention knowledge, diminished from immediately post-intervention to 6 months or after the clinical encounter. The increase in decision conflict may also reflect a diminished patient outcome since significantly fewer women were in the decision 
implementation phase according to the DCS. Nearly a quarter of women expressed interest in chemoprevention uptake after completing RealRisks, yet few women were referred for high-risk consultations and none of the participants had initiated chemoprevention at 6 months. Perhaps linking use of the DA more proximally to the clinical encounter will improve our patient reported outcomes. In future work, we have incorporated alerts and other cues to remind the patient to complete the RealRisks DA within a week prior to the clinical encounter.

Similar to previous studies, our intervention demonstrated that decision aids improve knowledge in those who use them. However, also like previous studies, increased knowledge does not lead to increased chemoprevention uptake for the purpose of reducing breast cancer risk. Improved accuracy of risk perceptions is an important measure of the quality of a decision aid [57], and while this is a prerequisite to informed decision making, it is difficult to know if this results in clinically useful decision making. Even when breast cancer risk seems to be understood, willingness to take chemoprevention medication remains low among women who are identified as eligible based on their Gail risk score [14, 58]. Previous research has demonstrated that health decision making may be based on heuristics and feelings, rather than on an accurate understanding of risk information [59, 60]. As such, individuals may not always process and act upon the risk information presented to them in the ways that healthcare providers intend. In addition to precise probabilistic risk information, lived experiences and particularly individual experiences with cancer have been shown to influence chemoprevention decisions $[58,61]$.

Several studies have demonstrated that recommendations from physicians and effective communication greatly affect patients' decision making in chemoprevention uptake [43]. Based upon data from key informant interviews, we found that PCPs reveal unfamiliarity with breast cancer risk assessment tools such as the Gail Model and a lack of confidence in prescribing chemoprevention. PCPs also reveal a preference to refer their patients to specialists for consultation about breast cancer risk reduction options, which may imply that the they were not well-informed about breast cancer preventive strategies available to patients [25]. Although all high-risk women and PCPs were given information on the CUMC breast clinic for high-risk consultations, it appears this was insufficient to alter practice patterns for most PCPs.

Trials of decision support tools designed to increase uptake of breast cancer chemoprevention targeting both patients and providers have been limited. Uptake remains low [14], [15] and as demonstrated in a randomized controlled trial of the BreastCARE intervention discussions about chemoprevention were still limited
[16]. This prior literature suggests that just targeting high-risk women or PCPs alone is ineffective. Additional work remains to better understand the impact of decision aids targeting both patients and providers.

\section{Limitations}

Limitations of our study include the lack of a concurrent control arm, the relatively small sample size, and conducting the study in an urban academic center with access to a high-risk clinic, all of which limit the generalizability of our findings. In addition, although we found no significant differences in age, race, and racial distribution between the pilot sample and KYRAS high-risk patients, our sample was self-selected from the larger KYRAS screening study. The study sample was older than what we expected and may not be totally representative of a higher risk younger population who are likely more appropriate for chemoprevention and the RealRisks DA. Additionally, we had higher than anticipated loss to follow-up of about $20 \%$. Our short-term follow-up of 6 months may have been insufficient to assess clinical outcomes such as high-risk clinic referrals and actual chemoprevention uptake.

\section{Conclusions}

We developed decision support tools for both patients and their PCPs, which include personalized risk reports and education about breast cancer risk and chemoprevention. Our study population was racially and ethnically diverse and our patient-centered DA, which is available in English and Spanish, was rigorously tested in women of multiple ethnicities with varying levels of health literacy and numeracy. In addition to using validated outcome measures, we were able to assess referrals to the high risk breast clinic and actual chemoprevention uptake using electronic health records.

The results of our initial pilot study have informed the design and conduct of a larger randomized controlled trial of 300 high-risk women assigned to standard educational materials alone or in combination with RealRisks and BNAV (NCT03069742). We will target younger, healthier women with higher breast cancer risk, including those with high-risk benign breast lesions such as atypical hyperplasia and lobular carcinoma in situ. These women are likely to derive a greater benefit from breast cancer risk reduction and a lower risk of serious side effects. To reinforce use of the patient-centered RealRisks DA, we will set up automated reminders to revisit the tool prior to their next PCP clinical encounter, next screening mammography visit, and birthday (as breast cancer risk increases with advancing age). We will enhance provider engagement with an enhanced $B N A V$ tool, which will offer continuing medical education (CME) credit and additional modules on breast cancer 
screening and other topics relevant to PCPs. We have already developed modules on risk communication and shared decision making. We will elicit patient preferences for chemoprevention, specifically factors that are most important and least important to chemoprevention decisions, which we will summarize for providers prior to the clinical encounter. Even if we do not observe a significant increase in chemoprevention uptake with the addition of RealRisks and BNAV compared to standard educational materials, our goal is to also increase informed choice, decrease decision conflict, and facilitate SDM during the clinical encounter. Facilitating discussions about breast cancer chemoprevention between clinicians and high-risk women is in accordance with recommendations from the U.S. Preventive Services Task Force (USPSTF), American Society for Clinical Oncology (ASCO), National Comprehensive Cancer Network (NCCN), and the National Institute for Health and Care Excellence (NICE) [8-11].

\section{Abbreviations}

Als: Aromatase inhibitors; ASCO: American Society for Clinical Oncology; BNAV: Breast cancer risk NAVigation decision support tool; DA: Decision aid; HBOC: Hereditary breast and ovarian cancer syndrome; NCCN: National Comprehensive Cancer Network (NCCN); NICE: National Institute for Health and Care Excellence; PCPs: Primary care providers; SDM: Shared decisionmaking; SERMS: Selective estrogen receptor modulators; USPSTF: U.S. Preventive Services Task Force

\section{Acknowledgements}

We thank all participants in this study. We also thank Jill Dimond and Margaret Sin, and Jeffery Wood for programming assistance.

\section{Funding}

This study was funded by the National Cancer Institute; NCI R01 CA177995$01 \mathrm{~A} 1$. The funder had no role in the design of the study, collection, analysis and interpretation of data, or writing the manuscript.

\section{Availability of data and materials}

The datasets used and/or analyzed during the current study are available from the corresponding author on reasonable request.

\section{Declarations}

The work complies with Ethics Policies of the journal.

\section{Authors' contributions}

RK and KDC conceptualized and designed the study. AV contributed to the acquisition of data. JF, AV and KDC analyzed the data and RK, TS, and KDC interpreted the results. All authors contributed to the writing of the paper, read and approved the final version of the paper.

\section{Ethics approval and consent to participate}

This study was approved by the Institutional Review Board of Columbia University, IRB AAAP4151. Informed consent was obtained from all individual participants included in the study. Consent to participate was given in written form. All procedures performed involving human participants were in accordance with the ethical standards of the institutional and/or national research committee and with the 1964 Helsinki declaration and its later amendments or comparable ethical standards.

\section{Consent for publication}

Not applicable.

\section{Competing interests}

The authors declare that they have no competing interests.

\section{Publisher's Note}

Springer Nature remains neutral with regard to jurisdictional claims in published maps and institutional affiliations.

\section{Author details}

${ }^{1}$ Columbia University, Mailman School of Public Health, 622 West 168th Street, PH-20, New York, NY 10032, USA. ${ }^{2}$ Columbia University, College of Physicians and Surgeons, New York, NY, USA. ${ }^{3}$ Herbert Irving Comprehensive Cancer Center, New York, NY, USA.

Received: 2 May 2018 Accepted: 3 December 2018 Published online: 17 December 2018

\section{References}

1. Ferlay J, Soerjomataram I, Dikshit R, et al. Cancer incidence and mortality worldwide: sources, methods and major patterns in GLOBOCAN 2012. Int J Cancer. 2015;136(5):E359-86.

2. American Cancer Society. Cancer Facts \& Figures 2017. 2017; https://www. cancer.org/research/cancer-facts-statistics/all-cancer-facts-figures/cancerfacts-figures-2017.html.

3. Costantino JP, Gail MH, Pee D, et al. Validation studies for models projecting the risk of invasive and total breast cancer incidence. J Natl Cancer Inst. 1999;91(18):1541-8.

4. Fisher B, Costantino JP, Wickerham DL, et al. Tamoxifen for the prevention of breast cancer: current status of the National Surgical Adjuvant Breast and bowel project P-1 study. J Natl Cancer Inst. 2005;97(22):1652-62.

5. Cuzick J, Sestak I, Cawthorn S, et al. Tamoxifen for prevention of breast cancer: extended long-term follow-up of the IBIS-I breast cancer prevention trial. Lancet Oncol. 2015;16(1):67-75.

6. Cuzick J, Sestak I, Forbes JF, et al. Anastrozole for prevention of breast cancer in high-risk postmenopausal women (IBIS-II): an international, double-blind, randomised placebo-controlled trial. Lancet. 2014;383(9922):1041-8.

7. Goss PE, Ingle JN, Ales-Martinez JE, et al. Exemestane for breast-cancer prevention in postmenopausal women. N Engl J Med. 2011;364(25):2381-91.

8. Nelson HD, Smith ME, Griffin JC, Fu R. Use of medications to reduce risk for primary breast cancer: a systematic review for the U.S. preventive services task force. Ann Intern Med. 2013;158(8):604-14.

9. Wise J. NICE recommends preventive drugs for breast cancer. BMJ. 2013; 346:f4116.

10. Bevers TB. NCCN Clinical Practice Guidelines in Oncology: Breast Cancer Risk Reduction. 2012; https://www.nccn.org/professionals/physician_gls/default. aspx\#breast.

11. Visvanathan K, Chlebowski RT, Hurley P, et al. American society of clinical oncology clinical practice guideline update on the use of pharmacologic interventions including tamoxifen, raloxifene, and aromatase inhibition for breast cancer risk reduction. J Clin Oncol. 2009;27(19):3235-58.

12. Ropka ME, Keim J, Philbrick JT. Patient decisions about breast cancer chemoprevention: a systematic review and meta-analysis. J Clin Oncol. 2010;28(18):3090-5.

13. Smith SG, Sestak I, Forster A, et al. Factors affecting uptake and adherence to breast cancer chemoprevention: a systematic review and meta-analysis. Ann Oncol. 2016;27(4):575-90.

14. Fagerlin A, Dillard AJ, Smith DM, et al. Women's interest in taking tamoxifen and raloxifene for breast cancer prevention: response to a tailored decision aid. Breast Cancer Res Treat. 2011;127(3):681-8.

15. Owens WL, Gallagher TJ, Kincheloe MJ, Ruetten VL. Implementation in a large health system of a program to identify women at high risk for breast cancer. J Oncol Pract. 2011;7(2):85-8.

16. Kaplan CP, Livaudais-Toman J, Tice JA, et al. A randomized, controlled trial to increase discussion of breast cancer in primary care. Cancer Epidemiol Biomark Prev. 2014;23(7):1245-53.

17. Legare F, Robitaille H, Gane C, Hebert J, Labrecque M, Rousseau F. Improving decision making about genetic testing in the clinic: an overview of effective knowledge translation interventions. PLoS One. 2016;11(3):e0150123.

18. Holmberg C, Bandos H, Fagerlin A, et al. NRG oncology/National Surgical Adjuvant Breast and bowel project decision-making Project-1 results: decision making in breast Cancer risk reduction. Cancer Prev Res (Phila). 2017;10(11):625-34.

19. Korfage IJ, Fuhrel-Forbis A, Ubel PA, et al. Informed choice about breast cancer prevention: randomized controlled trial of an online decision aid intervention. Breast Cancer Res. 2013;15(5):R74. 
20. Meiser B, Wong WKT, Peate M, Julian-Reynier C, Kirk J, Mitchell G. Motivators and barriers of tamoxifen use as risk-reducing medication amongst women at increased breast cancer risk: a systematic literature review. Hered Cancer Clin Pract. 2017;15:14.

21. Coe AM, Ueng W, Vargas JM, et al. Usability testing of a web-based decision aid for breast Cancer risk assessment among multi-ethnic women. AMIA Annu Symp Proc. 2016;2016:411-20

22. McGuinness J, Ueng W, Trivedi MS, et al. Factors associated with false positive results on screening mammography in a population of predominantly Hispanic women (in press). Cancer Epidemiol Biomark Prev. 2017.

23. Kukafka $\mathrm{R}, \mathrm{Yi} \mathrm{H}, \mathrm{Xiao} \mathrm{T}$, et al. Why breast Cancer risk by the numbers is not enough: evaluation of a decision aid in multi-ethnic, low-numerate women. J Med Internet Res. 2015;17(7):e165.

24. A I. The theory of planned behavior. Organ Behav Hum Decis Process. 1991.

25. Yi H, Xiao T, Thomas PS, et al. Barriers and facilitators to patient-provider communication when discussing breast Cancer risk to aid in the development of decision support tools. AMIA Annu Symp Proc. 2015;2015:1352-60.

26. Chew LD, Bradley KA, Boyko EJ. Brief questions to identify patients with inadequate health literacy. Fam Med. 2004;36(8):588-94.

27. Lipkus IM, Samsa G, Rimer BK. General performance on a numeracy scale among highly educated samples. Med Decis Mak. 2001;21(1):37-44.

28. Mandelblatt J, Kaufman E, Sheppard VB, et al. Breast cancer prevention in community clinics: will low-income Latina patients participate in clinical trials? Prev Med. 2005;40(6):611-8.

29. Williams GC, Rodin GC, Ryan RM, Grolnick WS, Deci EL. Autonomous regulation and long-term medication adherence in adult outpatients. Health Psychol. 1998;17(3):269-76.

30. Lipkus IM, Kuchibhatla M, McBride CM, et al. Relationships among breast cancer perceived absolute risk, comparative risk, and worries. Cancer Epidemiol Biomarkers Prev. 2000;9(9):973-5.

31. Armstrong K, Micco E, Carney A, Stopfer J, Putt M. Racial differences in the use of BRCA1/2 testing among women with a family history of breast or ovarian cancer. JAMA. 2005;293(14):1729-36.

32. Lerman C, Trock B, Rimer BK, Boyce A, Jepson C, Engstrom PF. Psychological and behavioral implications of abnormal mammograms. Ann Intern Med. 1991;114(8):657-61.

33. O'Connor AM. Validation of a decisional conflict scale. Med Decis Mak. 1995; 15(1):25-30.

34. Kreuter MW, Strecher VJ. Changing inaccurate perceptions of health risk: results from a randomized trial. Health Psychol. 1995;14(1):56-63.

35. Daly MB, Lerman CL, Ross E, Schwartz MD, Sands CB, Masny A. Gail model breast cancer risk components are poor predictors of risk perception and screening behavior. Breast Cancer Res Treat. 1996;41(1):59-70.

36. Stalmeier PF, Unic IJ, Verhoef LC, Van Daal WA. Evaluation of a shared decision making program for women suspected to have a genetic predisposition to breast cancer: preliminary results. Med Decis Mak. 1999; 19(3):230-41.

37. Graves KD, Huerta E, Cullen J, et al. Perceived risk of breast cancer among Latinas attending community clinics: risk comprehension and relationship with mammography adherence. Cancer Causes Control. 2008;19(10):1373-82.

38. LeBlanc A, Kenny DA, O'Connor AM, Legare F. Decisional conflict in patients and their physicians: a dyadic approach to shared decision making. Med Decis Mak. 2009;29(1):61-8.

39. Izadi S, Pachur T, Wheeler C, McGuire J, Waters EA. Spontaneous mental associations with the words "side effect": implications for informed and shared decision making. Patient Educ Couns. 2017;100(10):1928-33.

40. Hoerger $M$, Scherer LD, Fagerlin A. Affective forecasting and medication decision making in breast-cancer prevention. Health Psychol. 2016;35(6): 594-603.

41. Waters EA, Weinstein ND, Colditz GA, Emmons K. Explanations for side effect aversion in preventive medical treatment decisions. Health Psychol. 2009;28(2):201-9.

42. Waters EA, Weinstein ND, Colditz GA, Emmons KM. Reducing aversion to side effects in preventive medical treatment decisions. J Exp Psychol Appl. 2007;13(1):11-21.

43. Bober SL, Hoke LA, Duda RB, Regan MM, Tung NM. Decision-making about tamoxifen in women at high risk for breast cancer: clinical and psychological factors. J Clin Oncol. 2004;22(24):4951-7.

44. Metcalfe KA, Snyder C, Seidel J, Hanna D, Lynch HT, Narod S. The use of preventive measures among healthy women who carry a BRCA1 or BRCA2 mutation. Familial Cancer. 2005;4(2):97-103.
45. Salant T, Ganschow PS, Olopade OI, Lauderdale DS. "why take it if you don't have anything?" breast cancer risk perceptions and prevention choices at a public hospital. J Gen Intern Med. 2006;21(7):779-85.

46. Taylor R, Taguchi K. Tamoxifen for breast cancer chemoprevention: low uptake by high-risk women after evaluation of a breast lump. Ann Fam Med. 2005;3(3):242-7.

47. Port ER, Montgomery LL, Heerdt AS, Borgen PI. Patient reluctance toward tamoxifen use for breast cancer primary prevention. Ann Surg Oncol. 2001; 8(7):580-5.

48. Stacey D, O'Connor AM, DeGrasse C, Verma S. Development and evaluation of a breast cancer prevention decision aid for higher-risk women. Health Expect. 2003;6(1):3-18.

49. Melnikow J, Paterniti $D$, Azari $R$, et al. Preferences of women evaluating risks of tamoxifen (POWER) study of preferences for tamoxifen for breast cancer risk reduction. Cancer. 2005:103(10):1996-2005.

50. Juraskova I, Bonner C. Decision aids for breast cancer chemoprevention. Breast Cancer Res. 2013;15(5):106.

51. Anderson CJ. The psychology of doing nothing: forms of decision avoidance result from reason and emotion. Psychol Bull. 2003;129(1):139-67.

52. Luce MF. Choosing to avoid: coping with negatively emotion-laden consumer decisions. J Consum Res. 1998;24:409-33.

53. Martinez KA, Fagerlin A, Witteman HO, Holmberg C, Hawley ST. What matters to women when making decisions about breast Cancer chemoprevention? Patient. 2016:9(2):149-59.

54. Misra-Hebert AD, Kattan MW. Comment on: decisional conflict, regret, and the burden of rational decision making. Med Decis Mak. 2017;37(4):E360-1.

55. Vickers AJ. Response to "comment on: decisional conflict, regret, and the burden of rational decision making". Med Decis Mak. 2017;37(4):E362.

56. Vickers AJ. Decisional conflict, regret, and the burden of rational decision making. Med Decis Mak. 2017;37(1):3-5.

57. O'Connor AM, Fiset V, DeGrasse C, et al. Decision aids for patients considering options affecting cancer outcomes: evidence of efficacy and policy implications. J Natl Cancer Inst Monogr. 1999;(25):67-80.

58. Holmberg C, Waters EA, Whitehouse K, Daly M, McCaskill-Stevens W. My lived experiences are more important than your probabilities: the role of individualized risk estimates for decision making about participation in the study of tamoxifen and Raloxifene (STAR). Med Decis Mak. 2015;35(8):1010-22.

59. Reyna VF. A theory of medical decision making and health: fuzzy trace theory. Med Decis Mak. 2008;28(6):850-65.

60. Finucane $M L$, Alhakami A, Slovic $P$, J SM. The affect heuristic in judgments of risks and benefits. J Behav Decis Mak. 2000;13(1):1-17.

61. Padamsee TJ, Muraveva A, Yee LD, Wills CE, Paskett ED. Experiencing the cancer of a loved one influences decision-making for breast cancer prevention. J Health Psychol. 2017. https://doi.org/10.1177/1359105317746480.

Ready to submit your research? Choose BMC and benefit from:

- fast, convenient online submission

- thorough peer review by experienced researchers in your field

- rapid publication on acceptance

- support for research data, including large and complex data types

- gold Open Access which fosters wider collaboration and increased citations

- maximum visibility for your research: over $100 \mathrm{M}$ website views per year

At BMC, research is always in progress.

Learn more biomedcentral.com/submission 